\title{
Indian herbal remedies for diabetes as a cause of lead poisoning
}

\author{
R.W. Keen, A.C. Deacon', H.T. Delves², J.A. Moreton² and P.G. Frost \\ Central Middlesex Hospital, Acton Lane, London NW10 7NS, ${ }^{1}$ Northwick Park Hospital, Watford Road, \\ Harrow, Middlesex HA1 3 UJ and ${ }^{2}$ Department of Clinical Biochemistry, Southampton General Hospital, \\ Southampton SO9 $4 X Y, U K$
}

\begin{abstract}
Summary: Herbal remedies from the Indian subcontinent have been found to have high concentrations of heavy metals and unsupervised treatment may result in toxicity. We report the case of an Indian patient with hepatitis who was found to have lead poisoning where the source was traced to ethnic remedies he had been taking for diabetes.
\end{abstract}

\section{Introduction}

There is much public interest in alternative medicines which are assumed to be safe and free of side effects. The presence of toxic active ingredients or contaminants in these preparations can, however, result in adverse reactions with multi-system involvement. Some herbal remedies contain material other than of vegetable origin. Ayurveda, a traditional type of Indian medicine, uses lead and mercury as active constituents. Lead toxicity has been reported following the use of ethnic remedies in the treatment of haemorrhoids, ${ }^{1}$ teething pains ${ }^{2}$ and psoriasis. ${ }^{3}$

We report the case of an Indian man with lead poisoning where the source was traced to herbal remedies he had been taking for diabetes mellitus.

\section{Case report}

A 39 year old Indian man presented with a 10 day history of malaise, anorexia and upper abdominal pain. He had been previously well with a 10 -year history of non-insulin-dependent diabetes, controlled on glibenclamide $10 \mathrm{mg}$ daily.

On examination he appeared unwell, clinically anaemic, icteric and pyrexial $\left(37.4^{\circ} \mathrm{C}\right)$. Blood pressure was $130 / 85 \mathrm{mmHg}$. Abdominal examination revealed minimal epigastric tenderness. Examination was otherwise unremarkable.

Initial investigations showed: haemoglobin 10.0 $\mathrm{g} / \mathrm{dl}$, white cell count $9.4 \times 10^{9} / 1$, platelets

Correspondence: $\quad$ R.W. Keen, $\quad$ B.Sc., $\quad$ M.R.C.P., Rheumatology Department, St Thomas' Hospital, Lambeth Palace Road, London SE1 7EH, UK.

Accepted: 16 September 1993
$265 \times 10^{9} / 1$ and ESR $5 \mathrm{~mm} /$ hour. The blood film was normocytic. Blood urea, electrolytes and dipstick urinalysis were normal. Glucose was $8.5 \mathrm{mmol} / \mathrm{l}$. Liver function tests: alanine aminotransferase (ALT) $222 \mathrm{IU} / 1$ (2-29), aspartate aminotransferase (AST) 75 IU/1 (15-37), bilirubin $45 \mathrm{mmol} / \mathrm{l}(2-17)$. Amylase was normal. Serology to hepatitis viruses $A, B, C$, cytomegalovirus and Epstein-Barr virus was negative. Urinary porphyrin screen was positive.

Further investigations: urinary-5-aminolevulinic acid (5-ALA) $706 \mu \mathrm{mol} / 24$ hour $(<46)$ and coproporphyrin (predominately III isomer) $11,600 \mathrm{nmol} /$ 24 hour $(<250)$. Red cell zinc protoporphyrin $1,980 \mathrm{nmol} / 1(<1,600)$. Whole blood lead level: $5.3 \mu \mathrm{mol} / 1$ (reference range in non-exposed males of $<0.7)$.

The patient was treated with a calcium ethylenediaminetetra-acetate (EDTA) infusion $(2.4 \mathrm{~g})$ for 5 days. This was followed by a dramatic improvement in his symptoms, haematological and biochemical indices. Retrospective examination of his blood film revealed basophilic stippling on supravital staining.

There was no history of industrial or domestic lead exposure. Further inquiry revealed that for 6 weeks prior to admission he had been taking three medicines for diabetes, purchased in India. Samples were obtained and referred for analysis. A pale brown powder was found to have an inorganic lead content of $19 \%$ by weight. That this was the likely source was subsequently supported by the similarity in the ${ }^{206} \mathrm{~Pb}:{ }^{207} \mathrm{~Pb}$ ratios of the lead in the material and the patient's blood which were, respectively, $1.081 \pm 0.001(12)$ and $1.077 \pm$ 0.002 (7) (data are mean \pm s.d.(n)). The expected 
ratio for blood in UK residents with low lead exposure is $1.12-1.13^{4}$ and the decrease to 1.081 observed in the subject's blood must have been caused by intake of a lead source with a ratio of 1.08 or lower.

\section{Discussion}

This patient presented with features of a hepatitic condition and investigations were initially directed to exclude an infective cause. The fortuitous finding of elevated and characteristic urinary and blood porphyrins indicated the diagnosis of lead poisoning which promptly responded to chelation therapy. Lead poisoning can present acutely with hepatitis ${ }^{5}$ as in this case or as a chronic illness in which symptoms may be minimal. ${ }^{6}$

Herbal preparations from the Indian subcontinent have been shown previously to have a significant content of lead and other heavy metals ${ }^{7}$ which can result in mixed poisoning. ${ }^{1}$ Toxic features from other compounds were not apparent clinically and this was supported by the blood and substance analysis. The use of these preparations is not limited to the continent of origin and they may be in widespread use in ethnic populations in the United Kingdom. Doctors and patients should both be aware that ethnic herbal preparations may be the cause of unexplained symptoms and morbidity, and control over their use should be monitored. We believe this to be the first documented case where lead toxicity has occurred from an ethnic remedy taken for diabetes and its long-term complications. In Ayurvedic medicine, lead is regarded as an aphrodisiac and its reputed role may have been to counter the impotence associated with autonomic neuropathy in the diabetic male.

\section{Acknowledgement}

We should like to thank Dr Michael Newton for allowing us to report one of his patients.

\section{References}

1. Mitchell-Heggs, C.A.W., Conway, M. \& Cassar, J. Herbal medicine as a cause of combined lead and arsenic poisoning. Hum Exp Toxicol 1990, 9: 195-196.

2. Yu, C.L. \& Yeung, C.Y. Lead encephalopathy due to herbal medicine. Chin Med J 1987, 100: 915-917.

3. Smitherman, J. \& Harber, P. A case of mistaken identity: herbal medicine as a cause of lead toxicity. Am J Indust Med 1991, 20: 795-798.

4. Delves, H.T. Biomedical applications of ICP-MS. Chem Britain 1988, 24: 1009-1012.
5. Dunbain, D.W., Tallis, G.A., Popplewell, P.Y. \& Lee, R.A. Lead poisoning from Indian herbal medicine (Ayurveda). Med J Aust 1992, 157: 835-836.

6. Cullen, M.R., Robins, J.M. \& Eskenazi, B. Adult inorganic lead intoxication: presentation of 31 new cases and a review of recent advances in the literature. Medicine 1983, 62: 221-247.

7. McElvaine, M.D., Harder, E.M., Johnson, L., Baer, R.D. \& Satzger, R.D. Lead poisoning from the use of Indian folk medicines. JAMA 1990, 264: 2212-2213. 